\title{
Desempenho, qualidade dos ovos e balanço de nitrogênio de poedeiras comerciais alimentadas com rações contendo diferentes níveis de proteína bruta e lisina ${ }^{1}$
}

\author{
Mayra Fernanda Rizzo Silva², Douglas Emygdio de Faria², Paula Wick Rizzoli², Andréa \\ Luciana dos Santos ${ }^{2}$, Márcia Izumi Sakamoto², Henrique Rosa Baltazar de Souza ${ }^{2}$
}

\author{
1 Projeto financiado pela CAPES. \\ 2 Universidade de São Paulo, Faculdade de Zootecnia e Engenharia de Alimentos, Departamento de Zootecnia, Pirassununga, SP
}

RESUMO - O experimento foi conduzido para avaliar os efeitos de rações com diferentes níveis de proteína bruta (PB) e lisina sobre as características de desempenho, a qualidade interna dos ovos e o balanço/retenção do nitrogênio. Foram utilizadas 160 poedeiras Hisex White com 48 semanas de idade, alojadas individualmente em delineamento inteiramente casualizado em esquema fatorial $4 \times 2$, com quatro níveis de PB (12, 14, 16 e 18\%) e dois de lisina (0,85 e 1,00\%), totalizando oito rações com cinco repetições de quatro aves. O consumo de proteína bruta, o peso dos ovos, a massa de ovos e a porcentagem de albúmen apresentam resposta linear crescente aos níveis de PB na dieta. O balanço de nitrogênio não é alterado pelos níveis de proteína das rações.

Palavras-chave: aminoácido, exigências nutricionais, galinhas, ovos

\section{Performance, egg quality and nitrogen balance of commercial laying hens fed diets with different levels of crude protein and lysine}

\begin{abstract}
The experiment was carried out to evaluate the effects of diets with different levels of crude protein (CP) and lysine (LYS) on characteristics of performance, egg internal quality, and nitrogen balance/retention. It was used 160 Hisex White laying hens at 48 weeks of age, individually accomodated in a complete random design in a $4 \times 2$ factorial scheme with four levels of crude protein (12, 14, 16 and 18\%) and two levels of lysine (0.85 and 1.00\%), totalizing eight treatments with five replicates of four birds each. Crude protein intake, egg weight, egg mass and percentage of the albumen show increasing linear response to the levels of crude protein in the diet. Nitrogen balance is not altered by the levels of proteins in the diets.
\end{abstract}

Key Words: amino acids, egg, hens, nutritional requirements

\section{Introdução}

No início dos estudos de programas de alimentação para poedeiras, a ferramenta utilizada para avaliar a qualidade proteica de uma dieta era a proteína bruta. Com o surgimento da produção de aminoácidos sintéticos, os nutricionistas passaram a formular rações com menor custo e níveis mais adequados de aminoácidos, porém ainda com elevados níveis de proteína.

Atualmente, a maioria das pesquisas é desenvolvida com aminoácidos digestíveis, mas, segundo Ceccantini \& Yuri (2008): o valor de aminoácidos totais ainda serve como base para formulações, uma vez que traz uma maior precisão das necessidades nutricionais em relação ao teor de proteína bruta; existe grande número de dados publicados com o valor de aminoácidos totais dos ingredientes e das necessidades desses aminoácidos calculadas para cada fase da ave; e os principais macroingredientes utilizados (milho e farelo de soja) apresentam menor variação relativa entre os valores dos aminoácidos totais e os digestíveis.

A redução do conteúdo proteico e a suplementação da ração com aminoácidos industriais são os principais recursos para redução da excreção de nitrogênio (Waibel et al., 2000) e otimização do custo com alimentação. Além disso, diminui o incremento calórico, associado ao catabolismo do excesso de aminoácidos ingeridos (Leeson \& Summers, 1997, citados por Silva et al., 2006), e melhora a eficiência de utilização dos nutrientes, otimizando a produção de ovos (Rostagno et al., 1996). A simples redução no nível de proteína, sem a devida suplementação

Recebido em 21/11/2008 e aprovado em 5/6/2009.

Correspondências devem ser enviadas para: defaria@usp.br 
dos aminoácidos essenciais, diminui o consumo de ração e a produção de ovos, além de alterar o comportamento social das aves, resultando em canibalismo (Peganova \& Eder, 2003).

Estudos passados demonstram desempenho inferior das aves quando se compara a utilização de níveis reduzidos com níveis convencionais de proteína bruta (Keshavarz \& Jackson, 1992; Summers,1993; Leeson \& Caston, 1996), mas os resultados tendem a ser cada vez mais satisfatórios com o melhor conhecimento da composição das matérias-primas em relação ao conteúdo de aminoácidos totais e digestíveis e o maior domínio dos requerimentos nutricionais de aminoácidos para poedeiras, bem como a razão existente entre eles.

Os objetivos neste trabalho foram avaliar níveis de proteína bruta e lisina e seus efeitos sobre as características de desempenho, a qualidade dos ovos e o balanço de nitrogênio em poedeiras comerciais.

\section{Material e Métodos}

Foram utilizadas 160 poedeiras da linhagem Hisex White com 48 semanas de idade, alojadas individualmente em gaiolas metálicas medindo $0,25 \mathrm{~m} \times 0,40 \mathrm{~m} \times 0,45 \mathrm{~m}$ (largura, altura e profundidade, respectivamente) por um período experimental total de oito semanas, sendo as duas primeiras para adaptação. Utilizou-se delineamento experimental inteiramente casualizado em arranjo fatorial $4 \times 2$, com os fatores: níveis de proteína bruta (12, 14, 16 e 18\%) e lisina $(0,85$ e $1,00 \%)$, totalizando oito tratamentos com cinco repetições de quatro aves cada.

As temperatura $\left({ }^{\circ} \mathrm{C}\right)$ e umidade (\%) máximas e mínimas durante o período experimental foram de 26,3 e $13,9^{\circ} \mathrm{C}$ e $75 \%$ e $41 \%$, respectivamente. As aves receberam um total de 17 horas diárias de luz, sendo o alimento e a água fornecidos ad libitum.

As dietas foram formuladas após análise da matéria seca e da proteína bruta, conforme metodologia descrita por Silva (1998), e análise de aminoácidos, pela técnica de High Performance Liquid Chromatography, descrita pela Association of Official Analytical Chemists International (AOAC, 1997), dos principais ingredientes utilizados, como milho, farelo de soja e farelo de glúten de milho (Tabela 1). Por segurança e precisão experimental, as rações experimentais também foram analisadas (Tabela 2).

Os níveis de metionina, triptofano e valina obtidos com a formulação das dietas guardaram uma correspondência de no mínimo 47, 18 e 81\%, respectivamente, em relação aos valores de lisina. Todas as dietas foram isocalóricas, isocálcicas e isosódicas, assim como os níveis de fósforo disponível e de ácido linoleico. Os níveis de aminoácidos das dietas foram mantidos mesmo com a prática da redução proteica das dietas, de acordo com a Tabela Brasileira de Exigências Nutricionais (Rostagno et al., 2000).

Foram avaliadas as características de desempenho: consumo de ração (g/ave/dia), consumo de proteína bruta (g/ave/dia), consumo de lisina (g/ave/dia), consumo de energia metabolizável (kcal/ave/dia), produção de ovos (\% ovos/ave/dia), peso dos ovos (g), massa de ovos (g/ave/dia) e conversão alimentar (g ração/g ovo). As características de qualidade interna do ovo unidade Haugh e porcentagens de gema e albúmen foram avaliadas utilizando-se dois ovos por parcela experimental em dois dias da semana.

Após o período experimental, as aves foram transferidas para gaiolas providas de bandejas para a coleta de excretas durante três dias, mantendo-se os tratamentos, porém com três repetições de duas aves cada. Realizou-se a quantificação do nitrogênio das dietas experimentais e das excretas pelo método de micro Kjeldahl para cálculo do balanço de nitrogênio (diferença entre o nitrogênio ingerido e o excretado) e da retenção de nitrogênio (relação entre o balanço de nitrogênio e o total de nitrogênio ingerido multiplicado por 100).

Os dados experimentais foram analisados por meio do pacote estatístico SAS ${ }^{\circledR}$ (1998). Os dados foram submetidos ao teste de uniformidade das variâncias para realização da análise de variância. A análise de regressão foi aplicada apenas para dados que proporcionaram efeito significativo de níveis de proteína bruta e interação entre níveis de proteína bruta e lisina. O nível de significância utilizado foi de no máximo 5\%.

Tabela 1 - Composição nutricional dos ingredientes (\%MN)

\begin{tabular}{lccc}
\hline Item & Milho & Farelo de soja & Glúten de milho \\
\hline Matéria seca & 91,56 & 90,52 & 90,88 \\
Proteína bruta & 8,94 & 47,40 & 55,41 \\
Lisina & 0,254 & 2,944 & 0,935 \\
Treonina & 0,321 & 1,800 & 1,956 \\
Metionina & 0,199 & 0,626 & 1,360 \\
Cistina & 0,200 & 0,662 & 1,003 \\
Metionina + cistina & 0,399 & 1,286 & 2,362 \\
Alanina & 0,613 & 2,073 & 5,620 \\
Arginina & 0,422 & 3,507 & 1,919 \\
Ácido aspártico & 0,583 & 5,389 & 3,575 \\
Ácido glutâmico & 1,519 & 3,532 & 2,797 \\
Glicina & 0,344 & 2,126 & 1,613 \\
Histidina & 0,249 & 1,239 & 1,165 \\
Isoleucina & 0,291 & 2,108 & 2,284 \\
Leucina & 0,972 & 3,722 & 10,340 \\
Fenilalanina & 0,407 & 2,401 & 3,598 \\
Serina & 0,422 & 2,445 & 3,598 \\
Tirosina & 0,332 & 1,653 & 3,130 \\
Valina & 0,387 & 2,268 & 2,922 \\
Triptofano ${ }^{1}$ & 0,060 & 0,660 & 0,280 \\
\hline
\end{tabular}

${ }^{1}$ Segundo Rostagno et al. (2000). 
Tabela 2 - Composição nutricional das dietas experimentais

\begin{tabular}{|c|c|c|c|c|c|c|c|c|}
\hline \multirow[t]{2}{*}{ Ingrediente } & \multicolumn{8}{|c|}{ Dieta experimental } \\
\hline & 1 & 2 & 3 & 4 & 5 & 6 & 7 & 8 \\
\hline Milho $^{1}$ & 67,79 & 67,73 & 64,08 & 63,99 & 60,72 & 60,62 & 55,86 & 57,15 \\
\hline Farelo de soja ${ }^{1}$ & 9,77 & 8,69 & 16,39 & 15,53 & 21,99 & 21,30 & 22,83 & 26,79 \\
\hline Calcário & 9,42 & 9,42 & 9,36 & 9,39 & 9,36 & 9,36 & 9,35 & 9,33 \\
\hline Farelo de glúten milho ${ }^{1}$ & 0,00 & 0,00 & 0,00 & 0,00 & 0,00 & 0,00 & 3,84 & 0,00 \\
\hline Fosfato bicálcico & 1,60 & 1,61 & 1,56 & 1,56 & 1,52 & 1,53 & 1,51 & 1,49 \\
\hline Sal & 0,40 & 0,40 & 0,38 & 0,38 & 0,37 & 0,37 & 0,37 & 0,36 \\
\hline Óleo vegetal & 2,01 & 2,02 & 2,09 & 2,11 & 2,17 & 2,18 & 2,23 & 2,27 \\
\hline DL-metionina & 0,206 & 0,283 & 0,171 & 0,248 & 0,143 & 0,218 & 0,094 & 0,190 \\
\hline L-lisina HCL & 0,497 & 0,729 & 0,261 & 0,485 & 0,061 & 0,279 & 0,000 & 0,084 \\
\hline L-triptofano & 0,050 & 0,084 & 0,08 & 0,041 & 0,000 & 0,005 & 0,000 & 0,000 \\
\hline L-treonina & 0,123 & 0,142 & 0,014 & 0,030 & 0,000 & 0,000 & 0,000 & 0,000 \\
\hline L-valina & 0,208 & 0,356 & 0,070 & 0,213 & 0,000 & 0,094 & 0,000 & 0,000 \\
\hline L-arginina & 0,128 & 0,167 & 0,000 & 0,000 & 0,000 & 0,000 & 0,000 & 0,000 \\
\hline L-isoleucina & 0,248 & 0,271 & 0,117 & 0,136 & 0,008 & 0,023 & 0,000 & 0,000 \\
\hline Suplemento vitamínico e mineral ${ }^{2}$ & 0,212 & 0,212 & 0,212 & 0,212 & 0,212 & 0,212 & 0,212 & 0,212 \\
\hline Inerte (caulim) & 7,345 & 7,875 & 5,213 & 5,674 & 3,447 & 3,810 & 3,702 & 2,132 \\
\hline Energia e nutrientes & \multicolumn{8}{|c|}{ Composição calculada } \\
\hline Energia metabolizável (kcal/kg) & 2750 & 2750 & 2750 & 2750 & 2750 & 2750 & 2750 & 2750 \\
\hline Proteína bruta (\%) & $12,0(11,54)^{3}$ & 12,0 & 14,0 & 14,0 & 16,0 & 16,0 & 18,0 & $18,0(18,6)^{3}$ \\
\hline Lisina (\%) & 0,85 & 1,00 & 0,85 & 1,00 & 0,85 & 1,00 & 0,85 & $1,00(0,85)^{3}$ \\
\hline Cálcio (\%) & 4,00 & 4,00 & 4,00 & 4,00 & 4,00 & 4,00 & 4,00 & 4,00 \\
\hline Fósforo total (\%) & 0,548 & 0,544 & 0,565 & 0,562 & 0,579 & 0,576 & 0,582 & 0,590 \\
\hline Fósforo disponível (\%) & 0,375 & 0,375 & 0,375 & 0,375 & 0,375 & 0,375 & 0,375 & 0,375 \\
\hline Sódio (\%) & 0,18 & 0,18 & 0,18 & 0,18 & 0,18 & 0,18 & 0,18 & 0,18 \\
\hline Ácido linoleico & 2,4 & 2,4 & 2,4 & 2,4 & 2,4 & 2,4 & 2,4 & 2,4 \\
\hline \multicolumn{9}{|l|}{ Aminoácidos totais (\%) } \\
\hline Metionina & $0,400(0,360)^{3}$ & 0,470 & 0,400 & 0,470 & 0,400 & 0,470 & 0,400 & $0,470(0,451)^{3}$ \\
\hline Metionina + cistina & $0,600(0,537)^{3}$ & 0,663 & 0,637 & 0,701 & 0,667 & 0,732 & 0,701 & $0,762(0,721)^{3}$ \\
\hline Triptofano & 0,153 & 0,180 & 0,153 & 0,180 & 0,179 & 0,180 & 0,193 & 0,208 \\
\hline Treonina & $0,515(0,49)^{3}$ & 0,515 & 0,515 & 0,515 & 0,591 & 0,578 & 0,665 & $0,666(0,684)^{3}$ \\
\hline Arginina & $0,755(0,725)^{3}$ & 0,755 & 0,845 & 0,815 & 1,027 & 1,003 & 1,110 & $1,181(1,190)^{3}$ \\
\hline Isoleucina & $0,648(0,633)^{3}$ & 0,648 & 0,648 & 0,648 & 0,648 & 0,648 & 0,732 & $0,731(0,734)^{3}$ \\
\hline Valina & $0,689(0,682)^{3}$ & 0,810 & 0,689 & 0,810 & 0,734 & 0,810 & 0,835 & $0,829(0,832)^{3}$ \\
\hline
\end{tabular}

${ }^{1}$ Perfil nutricional estabelecido conforme análise bromatológica (Tabela 1).

${ }^{2}$ Conteúdo por kg de ração: vit. A - 8000 UI; vit. D3 - 2.200 UI; vit. E - 20 mg; vit. K3 - 2 mg; vit. $B_{1}$ - 1 mg; vit. $B_{2}-4$ mg; vit. $B_{6}-2$ mg; vit. $B_{12}$ - 10 mcg; pantotenato de cálcio - $10 \mathrm{mg}$; niacina - $25 \mathrm{mg}$; colina - 207,13 mg; ácido fólico - 0,4 mg; biotina - 15 mcg, selênio - 0,2 mg; cobre - 7,8 mg; ferro - 30 mg; zinco - 65 mg; manganês $70 \mathrm{mg}$; iodo - $1 \mathrm{mg}$; antioxidante BHT - $120 \mathrm{mg}$; veículo q.s.p. - 1.000 g.

${ }^{3}$ Composição analisada.

\section{Resultados e Discussão}

Não houve interação $(\mathrm{P}>0,05)$ entre os níveis de proteína e lisina para as características de desempenho (Tabela 3). Para os níveis de proteína, verificou-se efeito linear positivo $(\mathrm{P}<0,01)$ sobre o consumo de proteína bruta $(\mathrm{Y}=1,2345 \mathrm{x}-$ 1,$\left.55 ; \mathrm{r}^{2}=99,74 \%\right)$. As dietas com maiores níveis de proteína bruta promoveram maior consumo do nutriente, devido ao consumo de ração não ter variado significativamente entre os tratamentos.

O peso dos ovos e a massa de ovos aumentaram linearmente $(\mathrm{P}<0,05)$ com o aumento dos níveis de proteína (Figura 1). Resultados semelhantes foram encontrados por Pinheiro et al. (1996) ao trabalharem com níveis de proteína bruta de $17 \%$ e $20 \%$. Entretanto, esses autores também verificaram maiores médias de produção de ovos e melhor conversão alimentar ao utilizarem o maior nível de proteína bruta, o que não foi constatado no presente estudo.

Maiores níveis proteicos na dieta influenciam positivamente o peso dos ovos, pois as poedeiras não são capazes de reservar proteína eficientemente para a sua mantença, sendo dependentes do consumo diário.

Para os níveis de lisina testados, verificou-se efeito $(\mathrm{P}<0,01)$ somente para a variável consumo de lisina, a qual se apresentou maior com o maior nível de lisina utilizado $(1,00 \%)$. Isso se deve à relação com o consumo de ração e a proporção do aminoácido na dieta. O menor nível avaliado ( $0,85 \%$ de lisina total) atende à exigência das aves, portanto não houve efeitos sobre o desempenho. Atualmente, poedeiras leves de 54 a 70 semanas necessitam de $0,724 \%$ de lisina digestível/ave/dia para maximizar a massa de ovos (Cupertino et al., 2009). 
Tabela 3 - Desempenho de poedeiras comerciais alimentadas com rações com diversos níveis de proteína bruta e lisina

\begin{tabular}{|c|c|c|c|c|c|c|c|c|c|c|}
\hline \multirow[t]{2}{*}{ Característica } & \multicolumn{4}{|c|}{ Proteína bruta (\%) } & \multicolumn{2}{|c|}{ Lisina (\%) } & \multicolumn{3}{|c|}{ Valor de P } & \multirow{2}{*}{$\begin{array}{l}\text { CV } \\
(\%)\end{array}$} \\
\hline & 12 & 14 & 16 & 18 & 0,85 & 1,00 & $\mathrm{~PB}$ & LIS & PB $x$ LIS & \\
\hline Consumo de ração (g/ave/dia) & 109,39 & 114,07 & 113,33 & 114,66 & 112,96 & 112,76 & 0,0946 & 0,8958 & 0,1139 & 4,19 \\
\hline Consumo de PB (g/ave/dia) & 13,13 & 15,97 & 18,13 & 20,64 & 17,02 & 16,91 & $<0,0001$ & 0,6105 & 0,1280 & 4,07 \\
\hline Consumo de lisina (mg/ave/dia) & 1014,14 & 1054,95 & 1047,69 & 1058,84 & $960,18 b$ & $1127,62 \mathrm{a}$ & 0,1228 & $<0,0001$ & 0,1490 & 4,11 \\
\hline Consumo de energia (kcal EM/ave/dia) & 300,82 & 313,70 & 311,67 & 315,31 & 310,65 & 310,10 & 0,0946 & 0,8960 & 0,1138 & 4,19 \\
\hline Produção de ovos (\% ovos/ave/dia) & 86,92 & 89,82 & 92,56 & 91,96 & 89,70 & 90,93 & 0,1178 & 0,4803 & 0,5332 & 5,92 \\
\hline Peso de ovos (g) & 62,78 & 64,47 & 65,34 & 65,87 & 64,93 & 64,30 & 0,0048 & 0,2889 & 0,8979 & 2,78 \\
\hline Massa de ovos (g/ave/dia) & 54,52 & 57,89 & 60,47 & 60,62 & 58,26 & 58,49 & 0,0020 & 0,8373 & 0,4128 & 5,99 \\
\hline Conversão alimentar (g ração/g ovo) & 2,02 & 1,99 & 1,89 & 1,91 & 1,96 & 1,94 & 0,1316 & 0,6780 & 0,8494 & 6,95 \\
\hline
\end{tabular}
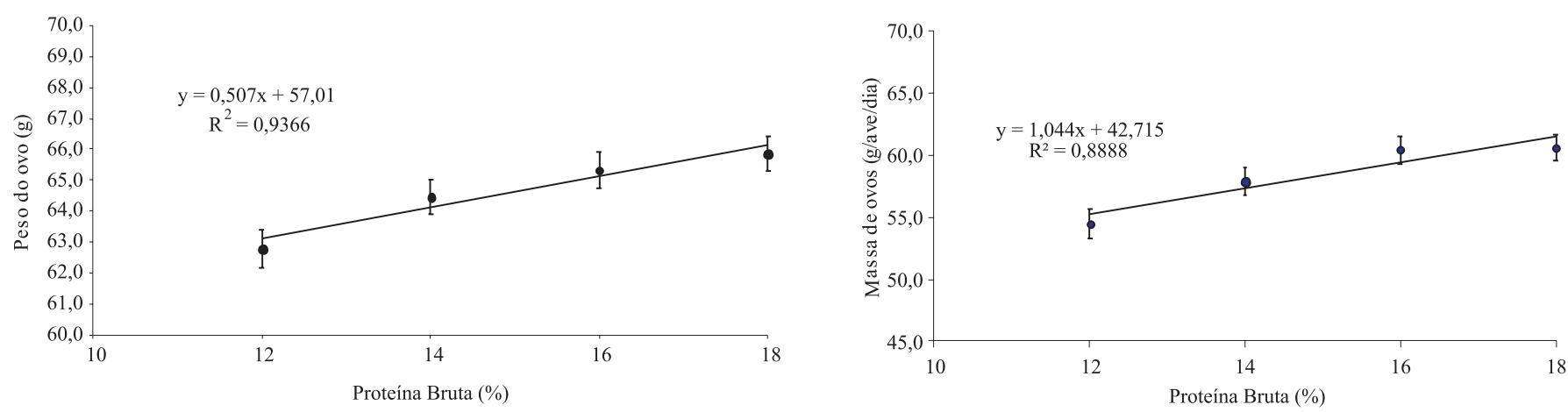

Figura 1 - Peso do ovo e massa de ovos de poedeiras comercias alimentadas com rações com diversos níveis de proteína bruta e lisina.

Ao reduzir os níveis de proteína bruta das dietas, estas foram suplementadas com aminoácidos para atender às exigências das aves. As características que apresentaram diferença significativa estão relacionadas diretamente com o aumento do consumo do nutriente e o peso do ovo. Todas as outras características estudadas não apresentaram diferença entre níveis de proteína bruta, demonstrando uma eficiência parcial da suplementação de aminoácidos quando da redução do nível de proteína bruta.

A proteína deve estar bem balanceada e ser de alta qualidade, para que a ave possa maximizar sua produção de ovos de maneira economicamente viável. A característica peso de ovos também sofre influência do nível de proteína utilizado, como foi verificado no presente trabalho, haja vista que para a síntese de albúmen a necessidade em proteína e aminoácido é alta e, portanto, qualquer decréscimo em tais nutrientes poderia ocasionar a redução dessa quantidade de albúmen, levando a um menor tamanho de ovo (Pesti et al., 2005).

Harms \& Russell (1993) verificaram que o desempenho de poedeiras, antes prejudicado por dietas com baixo teor proteico, foi recuperado quando receberam dietas suplementadas com aminoácidos. Keshavarz \& Austic (2004) observaram que dietas com $13 \%$ de proteína bruta mais a adição de metionina, lisina e triptofano, segundo o NRC (1994), proporcionaram resultados semelhantes aos de uma dieta convencional com 16\% de proteína bruta. Entretanto, quando se realiza redução proteica muito acentuada, como a estudada por Summers et al. (1991), com 10\% de proteína bruta, os aminoácidos não são capazes de proporcionar desempenho semelhante a dietas com níveis proteicos mais elevados. A resposta das aves à redução da proteína na ração parece estar condicionada à extensão em que esse nutriente é reduzido na ração.

Para as características de qualidade interna dos ovos, não houve interação $(\mathrm{P}>0,05)$ entre os fatores estudados (Tabela 4).

A porcentagem de albúmen apresentou comportamento linear crescente $(\mathrm{P}<0,05)$ em função dos níveis de proteína bruta da dieta (Figura 2). Já para os níveis de lisina, não foi verificado efeito $(\mathrm{P}>0,05)$ sobre a porcentagem de albúmen, discordando de Novak et al. (2004), que obtiveram maiores percentagens conforme se aumentaram os níveis. No entanto, o fato de que o aumento da porcentagem de albúmen não altera a unidade Haugh, citado por tais autores, também foi verificado neste estudo.

Não houve interação (P>0,05) entre os níveis de proteína e lisina para nenhuma das características. Os níveis de proteína bruta na dieta tiveram efeito $(\mathrm{P}<0,01)$ sobre as características ingestão e excreção de nitrogênio pelas aves (Tabela 5). Essas características estão diretamente relacionadas com a disponibilidade do nutriente na dieta quanto maior o nível de proteína bruta ingerida, maior a quantidade de nitrogênio excretado. Já o aproveitamento 
Tabela 4 - Qualidade interna do ovo de poedeiras comerciais alimentadas com diferentes níveis de proteína bruta e lisina

\begin{tabular}{|c|c|c|c|c|c|c|c|c|c|c|}
\hline \multirow[t]{2}{*}{ Característica } & \multicolumn{4}{|c|}{ Proteína bruta (\%) } & \multicolumn{2}{|c|}{ Lisina (\%) } & \multicolumn{3}{|c|}{ Valor de $\mathrm{P}$} & \multirow{2}{*}{$\begin{array}{l}C V \\
\text { (\%) }\end{array}$} \\
\hline & 12 & 14 & 16 & 18 & 0,85 & 1,00 & PB & LIS & $\mathrm{PB} \times$ LIS & \\
\hline \multicolumn{11}{|l|}{ Qualidade interna } \\
\hline Porcentagem de albúmen & 57,82 & 57,76 & 58,04 & 59,16 & 58,21 & 58,18 & 0,0124 & 0,9201 & 0,2987 & 1,71 \\
\hline Porcentagem de gema & 27,19 & 26,95 & 26,97 & 26,33 & 26,66 & 27,06 & 0,1535 & 0,1435 & 0,1968 & 3,12 \\
\hline Unidade Haugh & 84,58 & 84,04 & 83,86 & 83,94 & 84,64 & 83,57 & 0,9312 & 0,2011 & 0,8121 & 3,05 \\
\hline
\end{tabular}

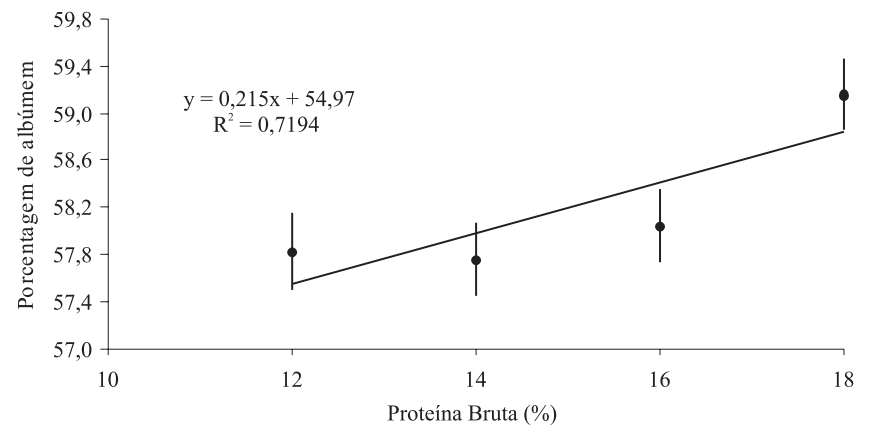

Figura 2 - Porcentagem de albúmen nos ovos de poedeiras comerciais alimentadas com rações com diversos níveis de proteína bruta e lisina. ocorre de maneira inversa, ou seja, quanto menor a disponibilidade do nitrogênio na dieta, melhor é o seu aproveitamento, mas no presente trabalho a retenção de nitrogênio não apresentou diferença significativa para os diferentes níveis de proteína (Tabela 5). Os resultados de ingestão e excreção encontrados estão de acordo com os relatados por Keshavarz \& Austic (2004).

Meluzzi et al. (2001), trabalhando com diferentes níveis de proteína bruta (13, 15 e 17\%), não constataram diferença na ingestão de nitrogênio. No entanto, os resultados de excreção de nitrogênio, os quais aumentaram conforme o aumento do nível de PB, concordam com o presente estudo. Esses autores verificaram ainda que a maior retenção de nitrogênio pela ave foi proporcionada por uma dieta que continha $15 \%$ de PB.

Tabela 5 - Ingestão, excreção, balanço e retenção do nitrogênio em poedeiras comerciais alimentadas com rações com diversos níveis de proteína bruta e lisina

\begin{tabular}{|c|c|c|c|c|c|c|c|c|c|c|}
\hline \multirow[t]{2}{*}{ Característica } & \multicolumn{4}{|c|}{ Proteína bruta (\%) } & \multicolumn{2}{|c|}{ Lisina (\%) } & \multicolumn{3}{|c|}{ Valor de P } & \multirow{2}{*}{$\begin{array}{l}\text { CV } \\
(\%)\end{array}$} \\
\hline & 12 & 14 & 16 & 18 & 0,85 & 1,00 & $\mathrm{~PB}$ & LIS & $\mathrm{PB} \times$ LIS & \\
\hline Ingestão de nitrogênio (g) & $8,86 c$ & $9,74 \mathrm{bc}$ & 11,98ab & $13,94 a$ & 11,30 & 10,96 & 0,0012 & 0,6974 & 0,9335 & 25,09 \\
\hline Excreção de nitrogênio (g) & $4,06 \mathrm{c}$ & $5,44 \mathrm{bc}$ & $6,20 \mathrm{ab}$ & $7,66 a$ & 5,46 & 5,90 & 0,0005 & 0,5572 & 0,8949 & 26,23 \\
\hline Balanço de nitrogênio (g) & 4,79 & 4,28 & 5,34 & 5,25 & 4,92 & 4,86 & 0,8008 & 0,8747 & 0,9907 & 51,00 \\
\hline Retenção de nitrogênio (\%) & 54,00 & 41,74 & 44,31 & 38,56 & 45,90 & 44,67 & 0,1008 & 0,8532 & 0,8479 & 29,58 \\
\hline
\end{tabular}

Médias seguidas pela mesma letra, em cada fator, não diferem $(\mathrm{P}>0,05)$ pelo teste Duncan.

${ }^{1}$ Valores com base em ingestão e excreção de duas aves por período de três dias (média entre parcelas).

\section{Conclusões}

A utilização de rações com $12 \%$ de proteína bruta suplementadas com aminoácidos não compromete a produção de ovos. O peso dos ovos, a massa de ovos e a porcentagem de albúmen respondem positiva e linearmente ao aumento dos níveis de proteína bruta. O balanço de nitrogênio não é alterado pelos níveis de proteína bruta da ração. As características de desempenho e qualidade interna dos ovos mantêm-se adequados quando a dieta contém $0,85 \%$ de lisina total.

\section{Referências}

ASSOCIATION OF OFFICIAL ANALYTICAL CHEMISTS INTERNATIONAL AOAC. Official methods of analysis. 16.ed. Gaitherburg: Patricia Cunniff, 1997. v.2, p.1141.

CECCANTINI, M.L.; YURI, D. Otimização da formulação de ração com base em aminoácidos digestíveis. In: CURSO DE ATUALIZAÇAO EM AVICULTURA PARA POSTURA COMERCIAL, 5., 2008, Jaboticabal. Anais... Jaboticabal: FCAV/UNESP, 2008. p.31-40.

CUPERTINO, E.S.; GOMES, P.C.; ALBINO, L.F.T. et al. Exigência nutricional de lisina digestível para galinhas poedeiras de 54 a 70 semanas de idade. Revista Brasileira de Zootecnia, v.38, n.3, p.480-487, 2009. 
HARMS, R.H.; RUSSELL, G.B. Optimizing egg mass with amino acid supplementation of a low-protein diet. Poultry Science, v.72, p.1892-1896, 1993.

KESHAVARZ, K.; JACKSON, M.E. Performance of growing pullets and laying hens fed low-protein, amino acidsupplemented diets. Poultry Science, v.71, p.905-918, 1992.

KESHAVARZ, K.; AUSTIC, R.E. The use of low-protein, lowphosphorus, amino acid and phytase supplemented diets on laying hen performance and nitrogen and phosphorus excretion. Poultry Science, v.83, p.75-83, 2004.

LEESON, S.; CASTON, L.J. Response of laying hens to diets varying in crude protein or available phosphorus. Journal Applied Poultry Research, v.5, n.3, p.289-296, 1996.

MELUZZI, A.; SIRRI, F.; TALLARICO, N. et al. Nitrogen retention and performance of brown laying hens on diets with different protein content and constant concentration of amino acids and energy. British Poultry Science, v.42, p.213-217, 2001.

NOVAK, C.; YAKULT, H.; SCHEIDELER, S. The combined effects of dietary lysine and total sulfur amino acid level on egg production parameters and egg components in Dekalb Delta laying hens. Poultry Science, v.83, p.977-984, 2004.

NATIONAL RESEARCH COUNCIL - NRC. Nutrient requirement of poultry. 9.ed. Washington, D.C.: National Academic Press, 1994. 155p.

PEGANOVA, S.; EDER, K. Interactions of various supplies of isoleucine, valine, leucine and tryptophan on the performance of laying hens. Poultry Science, v.82, p.100-105, 2003.

Pesti, G.M.; BAKalli, R.I.; DRIVER, J.P. et al. Poultry nutrition and feeding. Victoria: Trafford Publishing, 2005. 490 p.
PINHEIRO, J.W.; FONSECA, N.A.N.; MIZUBUTI, I.Y. et al. Níveis de energia metabolizável (EM) e de proteína bruta (PB) na ração sobre o desempenho de galinhas poedeiras. In: CONFERÊNCIA APINCO DE CIÊNCIA E TECNOLOGIA AVÍCOLAS, 1995, Curitiba. Anais... Curitiba: Fundação Apinco de Ciência e Tecnologia Avícolas. 1996. p.52.

ROSTAGNO, H.S.; BARBARINO JR., P.; BARBOSA, W.A. Exigências nutricionais das aves determinadas no Brasil. In: SIMPÓSIO INTERNACIONAL SOBRE EXIGÊNCIAS NUTRICIONAIS DE AVES E SUÍNOS, 1996, Viçosa, MG. Anais... Viçosa, MG: DZO, 1996. p.361-388.

ROSTAGNO, H.S.; ALBINO, L.F.T.; DONZELE, J.L. et al. Tabelas brasileiras para aves e suínos: composição de alimentos e exigências nutricionais. Viçosa, MG: Universidade Federal de Viçosa, 2000. 141p.

SILVA, D.J. Análise de alimentos: métodos químicos e biológicos. Viçosa, MG: UFV, 1998. 166p.

SILVA, E.L.; SILVA, J.H.V.; JORDÃO FILHO, J. et al. Redução dos níveis proteicos e suplementação com metionina e lisina em rações para poedeiras leves. Revista Brasileira de Zootecnia, v.35, n.2, p.491-496, 2006.

STATISTICAL ANALYSIS SYSTEM - SAS. User's guide. version 6.12, 4.ed, v.2, Cary: 1998. 842p.

SUMMERS, J.D. Reducing nitrogen excretion of the laying hen by feeding lower crude protein diets. Poultry Science, v.72, p.1473-1478, 1993.

SUMMERS, J.D.; ATKINSON, J.L.; SPRATT, D. Supplementation of a low-protein diet in an attempt to optimize egg mass output. Canadian Journal of Animal Science, v.71, p.211-220, 1991.

WAIBEL, P.E.; CARLSON, C.W.; BRANNON, J.A. et al. Limiting amino acids after methionine and lysine with growing turkeys fed low-protein diets. Poultry Science, v.79, p.1290-1298, 2000. 